\title{
GEVAREN OP FISCAAL GEBIED VOOR DE CONTINUIITEIT VAN DE ONDERNEMING
}

\author{
door D. Broer
}

In de economische structuur van de onderneming treedt de verhouding van leiding en vermogensverschaffing op de voorgrond. Hiervan uitgaande kunnen wij de ondernemingen onderscheiden in persoonlijke en onpersoonlijke ondernemingen. ${ }^{1}$ )

De persoonlijke ondernemingen worden gekenmerkt door het feit, dat de leider van het bedrijf tevens is de verschaffer van het vermogen. Bij de onpersoonlijke onderneming kan er een scheiding zijn tussen leiding en financiering. De onderneming kan daardoor een meer duurzaam karakter krijgen. $\mathrm{Z}_{\mathrm{ij}}$ is dan niet meer verbonden aan de persoon van een bepaalde ondernemer en is daarom ook niet meer in haar voortbestaan van deze afhankelijk.

De rechtsvormen, waarin de persoonlijke onderneming optreedt zijn voornamelijk de eenmanszaak, de vennootschap onder firma en de commanditaire vennootschap. Daarnaast vinden wij tegenwoordig de naamloze vennootschapsvorm voor de persoonlijke ondernemingen veelvuldig toegepast.

De continuilteit van de onderneming is voor allen die bij de onderneming betrokken zijn en ook maatschappelijk van groot belang. De ondernemer zal daarom de nodige voorzieningen moeten treffen, welke het voortbestaan van de onderneming verzekeren. Deze voorzieningen dienen de leiding en de vermogensverschaffing te omvatten. Bij het treffen van deze voorzieningen dient ter dege rekening te worden gehouden met de fiscale consequenties. In onze dynamische maatschappij is ook het belastingrecht geen onveranderlijke factor. Niet alleen worden de belastingwetten vaak gewijzigd of door andere vervangen, door arresten van de Gerechtshoven en de Hoge Raad kunnen bestaande situaties vrij plotseling grondig worden gewijzigd.

Het is daarom van groot belang, dat de ondernemer de fiscale gevolgen van de door hem getroffen en te treffen voorzieningen nauwkeurig overziet en bij elke wijziging in wetgeving en/of jurisprudentie nagaat dan wel doet nagaan of de aard van de voorzieningen, dan wel de juridische vormgeving, waarin deze zijn vervat, geen wijziging behoeft.

De gevaren op fiscaal gebied liggen uiteraard op het gebied der financiering, welke door fiscale eisen kan worden bemoeilijkt. De fiscale wetten welke hierbij een voorname rol spelen zijn de Successiewet 1956 en het Besluit op de Inkomstenbelasting 1941. Bij de Tweede Kamer der Staten-Generaal is thans in behandeling een wetsontwerp aangeduid als Wet op de inkomstenbelasting 1960, ter vervanging van het oude Besluit van 1941.

Het is dienstig bij de behandeling van de onderhavige fiscale problematiek een onderscheid te maken tussen

$1^{\circ}$ de rechtsvorm van de onderneming;

$2^{\circ}$ het uittreden van de ondernemer bij leven of het overlijden van de ondernemer.

1) Prof. Dr. J. L. Mey: Bedrijfseconomie, deel II.

m a b blz. 365 


\section{A. De eenmanszaak}

\section{Overdracht bij leven}

Wanneer de ondernemer wegens zijn gevorderde leeftijd de onderneming aan een ander wenst over te dragen, dan zal hij behalve het door hem in die onderneming geïnvesteerde kapitaal ook een vergoeding vragen voor de door hem gekweekte goodwill. Dit bedrag zal door zijn opvolger moeten worden gefinancierd. Men heeft hiervoor vroeger de constructie gekozen van het stamrecht. Voor de waarde van de goodwill kreeg de uittredende ondernemer een recht op een lijfrente. Zijn opvolger kon deze uit de winst voldoen. De fiscus eiste slechts haar deel van de uitgekeerde lijfrentetermijnen. Het arrest van de Hoge Raad van 17 oktober 1956 (BNB 1956/313) maakte aan deze constructie een einde door het gehele stamrecht belastbaar te verklaren, terwijl de later ontvangen lijfrentetermijnen eveneens belast bleven.

Met toepassing van de hardheidsclausule kan sedertdien deze constructie voor elk afzonderlijk geval worden gevraagd aan de Belastingdienst. De volgende eisen worden thans gesteld (resolutie 13 juli 1962, no. B 2/8750):

a) de belastingplichtige moet de 65-jarige leeftijd hebben bereikt of invalide zijn;

b) zijn vermogen (met inbegrip van het stamrecht) moet minder bedragen dan $f$ 100.000,一;

c) de lijfrente moet worden gesloten op het leven van de belastingplichtige en/of op dat van zijn echtgenote en terstond ingaan;

d) de lijfrente moet, indien zij door de belastingplichtige zelf wordt aangekocht, worden afgesloten bij een levensverzekeringmaatschappij;

e) de overdracht van het bedrijf of de beroepsuitoefening mag niet plaats vinden aan een N.V., waarin de belastingplichtige een aanmerkelijk belang in de zin van artikel 19, tweede lid van het Besluit op de Inkomstenbelasting 1941 heeft of zal verk rijgen.

Voorwaarden voor het buiten aanmerking laten van het stamrecht zijn:

1e de aftrek op de voet van artikel 16, eerste lid, 2e, letter d van het Besluit op de Inkomstenbelasting 1941 (lijfrentepremie) moet achterwege blijven;

$2 e$ op de vrijstelling van artikel 20 , derde lid van het Besluit (de franchise van $f 7.500$, - van de overdrachtswinst) mag geen beroep worden gedaan.

Door de eis dat het totale vermogen, met inbegrip van het stamrecht niet meer dan $f$ 100.000, - mag bedragen komen vele ondernemers voor de toepassing van deze regeling niet in aanmerking.

In de nieuwe Wet op de inkomstenbelasting 1960 is deze materie als volgt geregeld (artikel 17a):

„1. Ingeval in rechtstreeks verband met en uiterlijk zes maanden na het staken van een onderneming periodieke uitkeringen als bedoeld zijn in artikel 22, eerste lid, letter g (noot: lijfrenten!), worden bedongen, wordt de waarde welke daaraan ten tijde van het staken in het economisch verkeer kan worden toegekend, voorzover deze de winst behaald met of bij het staken niet te boven gaat, tot een bedrag van ten hoogste $f 100.000$, - ten laste van die winst gebracht, mits de uitkeringen: 
a. strekken ter verzorging van de gewezen ondernemer, zijn echtgenote en zijn minderjarige kinderen en pleegkinderen;

b. uitsluitend van het leven van de gerechtigden afhankelijk zijn en, voorzover zij aan de kinderen of pleegkinderen toekomen, tevens een einde nemen bij hun meerderjarigheid;

c. dadelijk dan wel, indien de verzorging niet mede de ondernemer zelf betreft, bij diens overlijden ingaan.

Het wetsvoorstel geeft een aanmerkelijke verruiming doordat het overig vermogen van de ondernemer buiten beschouwing wordt gelaten en onder de genoemde voorwarden maximaal $f$ 100.000, - via een lijfrenteverplichting kan worden gefinancierd.

\section{Overlijden van de ondernemer}

Bij het overlijden van de ondernemer eist de fiscus tweevoudig zijn tol:

\section{a) Successicrecht}

Krachtens de Successiewet 1956 wordt het recht van successie geheven van de warde van al wat krachtens erfrecht wordt verkregen van iemand die ten tijde van dat overlijden binnen het Rijk woonde.

Onder verlirijging krachtens erfrecht wordt mede verstaan de verkrijging van vergunningen en aanspraken bij of na het overlijden van de erflater, indien die verkrijging rechtstreeks verband (artikel $1,1 \mathrm{e}$ lid, $1^{\circ}$ van de Wet) houdt met de omstandigheid, dat de erflater die of dergelijke vergunningen of aanspraken bezat.

Bij de behandeling van de Successiewet 1956 in de Tweede Kaner der StatenGeneraal is de Minister teruggekomen van zijn oorspronkelijke opzet ook de goodwill met successierecht te belasten. Hij heeft toen evenwel artikel 21 der Wet de bepaling van het belastbar bedrag) aangevuld met een wardebepaling (verlioopwarde of geldswarde) van de bovengenoemde vergunningen en aanspraken. Ook werd toen bepaald, dat indien zaken behoren tot een beroeps- of bedrijfsvermogen het geheel dier zaken minstens moct worden gesteld op de prijs welke een gegadigde die voornemens zou zijn het beroep of bedrijf voort te zetten, voor de overneming van die zaken zou moeten besteden. Ingevolge bovenstaande bepalingen wordt ook successicrecht geheven over de warde van een drankvergunning (ook al wordt deze formeel niet vererfd, maar overgeschreven), cen teeltrecht, een bedrijfsvergunning van het productschap vis- en visproducten, een vervoersvergunning ingevolge de Wet Autovervoer Goederen, een autobusdienstvergunning ingevolge de Wet Autovervoer Personen, enz.

Het tarief van de Successierechten loopt voor vererving door kinderen en echtgenote op tot $17 \%$ (bij verkrijging boven $f 500.000$, - ; van $f$ 200.000, - tot $f 500.000$, - bedraage het recht $15 \%$ ), voor kleinkinderen bedragen deze percentages 22 en 20, voor broers en zusters 36 en 34 en nichten en neven (kinderen van broers en zusters) 45 en 43 .

\section{b) Inkomstenbelasting}

Op de meeste ondernemingen drukt door het gebruik maken van fiscale afschrijvingsmethoden (zoals de vervroegde afschrijving ingevolge artikel 8 van het Besluit op de Inkomstenbelasting 1941) een latente belastingverplichting. 
Een latente belastingverplichting is een verplichting jegens de fiscus, welke betrekking heeft op die gedeelten van de naar bedrijfseconomische regelen berekende winst, welke de fiscus, hetzij bij toepassing van de normale wetsregels, hetzij als gevolg van bijzondere fiscale voorschriften, voorlopig buiten heffing laat. ${ }^{2}$ )

Het bestaan van een latente belastingverplichting is in wezen een financiering op lange termijn door de fiscus.

De opzet van de Inkomstenbelasting is t.a.v. de ondernemer alle door hem gemaakte winst over het gehele verloop van de onderneming te belasten. Winst is fiscaal dan ook ,, het bedrag van de gezamenlijke voordelen die, onder welke naam en in welke vorm ook, worden verkregen uit onderneming".

Artikel 7, lid 2 van het Besluit zegt nu:

„Voordelen uit bedrijf of zelfstandig uitgeoefend beroep, welke niet reeds ingevolge de regelen, geldende voor de jaarlijkse winst, in aanmerking worden genomen - zoals verschillen tussen de geldswaarde en de fiscale boekwaarde van tot het bedrijfs- of beroepsvermogen behorende zaken - behoren tot de winst van het laatste jaar, waarover hier te lande belastbare winst wordt genoten door degeen voor wiens rekening het bedrijf of beroep wordt uitgeoefend."

Bij overlijden van de ondernemer presenteert dus de fiscus zijn (eind)afrekening. Deze eindafrekeningswinst wordt - op verzoek - belast tegen $20 \%$. De stille reserves in de voorraden vallen bij de huidige wetgeving onder de normale jaarwinst van het laatste jaar en worden dus progressief belast. In het aanhangige wetsontwerp is ook voor de winst op voorraden het tarief op $20 \%$ gesteld.

De betaling van deze belasting kan de onderneming in grote moeilijkheden brengen. Vandaar, dat in het huidige Besluit een bepaling is opgenomen (artikel 44a), waardoor de belasting verschuldigd over de eindafrekeningswinst, indien het vermogen van de overledene voor tenminste de helft als bedrijfsvermogen moet worden aangemerkt, kan worden voldaan in vijf gelijke jaarlijkse termijnen. Zou de belasting contant worden afgerekend, dan krijgt men een korting van $8 \%$.

Deze betalingsfaciliteit is evenwel in het Wetsontwerp op de Inkomstenbelasting niet overgenomen, o.m. op grond van de overweging dat meermalen erfgenamen die zeer wel in staat zijn de belasting te voldoen deze wettelijke uitstelregeling verzoeken teneinde te kunnen profiteren van de bij contante betaling verleende korting. In de Memorie van Antwoord aan de Tweede Kamer over het Wetsontwerp merken de bewindslieden naar aanleiding van door kamerleden terzake gestelde vragen op, dat van geval tot geval kan worden bezien of voor de invordering een bijzondere regeling moet worden getroffen, waarbij een soepel standpunt zal worden ingenomen.

Het Wetsontwerp biedt ook nog een andere mogelijkheid. In artikel 15, 3e lid van het ontwerp is een regeling opgenomen die het mogelijk maakt de fiscale afrekening achterwege te laten, wanneer de gezamenlijke erfgenamen optreden als rechtstreekse voortzetters van de persoon van de overleden belastingplichtige, derhalve met onveranderde aanhouding van de oude boekwaarde en met instandhouding van de gevormde fiscale reserves. Het gevolg van deze doorschuifregeling is dat de gezamenlijke voortzetters in dezelfde positie komen te verkeren als waarin

2) Definitie rapport subcommissie C.A.B. van het N.I.v.A.

m a b blz. 368 
de voorganger zich bevond. Alle factoren welke voor het bepalen van de winst van de voorganger van belang waren, gaan ongewijzigd over op de voortzetters. De fiscale claim gaat derhalve mede.

De doorschuifregeling zal, naar het ons voorkomt, alleen haar nut hebben in die gevallen waar de rentabiliteit en/of de liquiditeit ongunstig zijn. Immers over de opwaardering bij overlijden wordt $20 \%$ belasting geheven. Wanneer de inkomens van de erfgenamen rond $f 20.000$, - liggen bedraagt het marginale percentage reeds $40 \%$, zodat via de hogere afschrijving de belasting over de overlijdenswinst dubbel wordt gecompenseerd!

\section{B. De vennootschap onder een firma}

In het vennootschapscontract moeten ter handhaving van de continuïteit van de onderneming bepalingen zijn opgenomen waardoor bij uittreding of overlijden van vennoten de onderneming in stand kan blijven. De overblijvende vennoten moeten in staat worden gesteld de financiering over te nemen, tenzij er maatregelen zijn getroffen waardoor in de opvolging door één of meer erfgenamen wordt voorzien.

Voorzover de kapitaaldeelname van een vennoot dient ter financiering van een permanente vermogensbehoefte, kan de belastingheffing bij uittreding of overlijden van de vennoot de onderneming in moeilijkheden brengen.

\section{Uittreding}

Met betrekking tot de vroeger algemeen gevolgde constructie waarbij tegenover de overdrachtswinst, inclusief de goodwill een recht op een lijfrente werd toegekend en de gevolgen van het stamrechtarrest van de Hoge Raad (BNB 1956/313) zij verwezen naar hetgeen in het voorgaande bij de eenmanszaak is opgemerkt.

$\mathrm{Bij}$ de firma, welke uiteraard in de leiding een grotere continuïteit kan bezitten dan een eenmanszaak, wordt bij uittreding ook wel een andere regeling toegepast. Men bedingt dan in plaats van een lijfrente een winstrecht. Fiscaal wordt namelijk dan aangenomen dat van voortgezette bedrijfsuitoefening sprake is. Goed koopmansgebruik laat toe deze winst tot uitdrukking te brengen naar gelang deze in de uitkeringen worden ontvangen. De overblijvende firmanten kunnen dan uit de winst hun vroegere vennoot uitbetalen. De consequentie voor de uitgetreden vennoot is wel dat de jaarlijks door hem ontvangen winstuitkeringen, wanneer zijn kapitaalsaldo is afgelost, tegen het normale (progressieve) tarief worden belast, doch deze consequentie gold ook voor de lijfrente-termijnen bij de stamrechtconstructie. De winstrechtconstructie biedt evenwel géén afdoende oplossing voorzover ze mede wordt bedongen ten behoeve van weduwe en wezen. Bij het overlijden van de vroegere vennoot komt de gekapitaliseerde waarde van het resterende winstrecht als eindafrekeningswinst naar voren, terwijl daarnaast de door begunstigden (weduwe en wezen) te genieten termijnen als opbrengst van roerend kapitaal ten volle aan de Inkomstenbelasting onderworpen blijven.

Bovendien wordt voor het successierecht het recht op een winstaandeel belast op grond van artikel 13 der Successiewet 1956 (beding ten behoeve van een derde).

De winstrechtconstructie leidt in deze gevallen dus tot zeer onaangename fiscale consequenties en is dan ook een ondeugdelijk middel.

Wel mogelijk is een overdracht van een firma-aandeel, waarvan het totale bedrag is vastgesteld, in termijnen met de restrictie dat de uitkeringen niet meer zullen 
bedragen dan een bepaald percentage van de winst. Deze restrictie behoeft niet mede te brengen dat van een stamrecht gesproken kan worden (BNB 1961/296). Wel wordt dan de gehele overdrachtswinst terstond belast en zal dus voor de financiering van deze belastingclaim moeten worden zorg gedragen.

\section{Overlijden van de ondernemer}

In vrijwel alle vennootschapscontracten komt een beding voor om te voorkomen dat de vennootschap door het overlijden van één der vennoten van rechtswege wordt ontbonden (artikel 1683 B.W.).

Men onderscheidt de bedingen als volgt:
a) voortzettingsbeding
b) toetredingsbeding
c) verblijvingsbeding
d) overnemingsbeding

Het voortzettingsbeding is het beding, bedoeld in artikel $1688 \mathrm{~B}$.W., waardoor de vennootschap in geval van overlijden van één der vennoten voortduurt òf met zijn gezamenlijke erfgenamen óf alleen tussen de overblijvende vennoten. Dit beding regelt evenwel niets over de eigendom van de firmazaken.

Het toetredingsbeding regelt de toetreding van vennoten, b.v. bij overlijden van een vennoot. Zo kan er bedongen worden dat een zoon van de overledene tot de vennootschap kan toetreden om het bedrijf met de langstlevende vennoten voort te zetten. Ook dit beding regelt niets over de eigendom van de firmazaken.

Het verblijvingsbeding is een beding waarbij het aan de overleden vennoot toekomende aandeel in het bedrijfskapitaal tegen een tevoren bepaalde prijs overgaat op zijn medevennoten. Deze prijs kan zijn de boekwaarde, maar ook de werkelijke waarde ten tijde van het overlijden. Dit is een overdracht onder de opschortende voorwaarde van vooroverlijden van de betrokken vennoot.

$\mathrm{Bij}$ het overnemingsbeding krijgen de overblijvende vennoten het recht het aandeel van de overleden vennoot over te nemen. Zij zijn echter niet verplicht tot overname. Er is voor hen sprake van een koopoptie.

Ten aanzien van de fiscale gevolgen kunnen we weer onderscheiden:

\section{a) Successierecht}

Aan hetgeen ter zake bij de behandeling van de eenmanszaak werd opgemerkt, kan nog het volgende worden toegevoegd. Wanneer een vennoot bij de vennostschapsacte het recht bedongen heeft dat bij zijn overlijden zijn weduwe commanditair vennote wordt, hebben we te maken met een belastbaar recht op grond van artikel 13 der Successiewet (P.W. no. 14374, in gelijke zin het arrest van de Hoge Raad, BNB 1962/59).

De Hoge Raad stelde bij het arrest van 3 januari 1962, dat de overleden vennoot in plaats van dat recht een aanzienlijke prestatie voor zichzelf had kunnen bedingen. Ofschoon formeel goodwill niet wordt belast met successierecht, wordt via artikel 13 (het beding ten behoeve van een derde) in deze gevallen de goodwill in wezen toch getroffen.

b) Inkomstenbelasting

Het hiervoor genoemde verblijvingsbeding heeft tot gevolg dat geen overlijdenswinst (te belasten a $20 \%$ ) wordt gemaakt, maar overdrachtswinst. Deze winst 
wordt belast op de wet van artikel 48 van het Besluit op de Inkomstenbelasting (ook in het Wetsontwerp op de inkomstenbelasting geregeld in artikel 48), hetgeen inhoudt dat de belastingvoet 20 tot $40 \%$ bedraagt, afhankelijk van het percentage dat over de laatste $f 600,-$ van het overig inkomen wordt geheven.

Terwijl het thans nog mogelijk is bij overlijden van een vennoot in het eerste gedeelte van een jaar door toepassing van fiscaal toegelaten vervroegde afschrijvingen (artikel 8, 3e lid van het Besluit) het overig inkomen terug te brengen tot een zodanig bedrag dat het marginale percentage $20 \%$ bedraagt, zal na invoering van de Wet op de inkomstenbelasting 1960 deze mogelijkheid uitgesloten zijn, daar dan een percentage gegrond op de gemiddelde tabelinkomens van de drie voorafgaande jaren wordt bepaald.

Wanneer een overnemingsbeding is gemaakt, is er sprake van overlijdenswinst, welke wordt belast tegen $20 \%$. Verder zij hiervoor verwezen naar de behandeling van de eindafrekeningswinst bij de eenmanszaak.

Ter financiering van de overname van het firma-aandeel door de overlevende vennoten sluit men veel af een compagnonsverzekering. Hierbij zal men, wil deze verzekering aan het gestelde doel kunnen beantwoorden de juiste vorm dienen te kiezen.

Wanneer de vennoten zich bij de vennootschapsacte verplichten een compagnonsverzekering ten name van de vennootschap te sluiten teneinde zeker te zijn dat bij het overlijden van één hunner contante middelen aanwezig zullen zijn, moet deze verzekering als deel van het bedrijfsvermogen worden beschouwd. De betaalde premies moeten dan worden geactiveerd (mogen dus niet als kosten worden geboekt). Bij uitkering van het kapitaal aan de vennootschap is het verschil tussen de uitkering en de boekwaarde winst voor de vennootschap. Het beoogde doel wordt daarmede echter niet bereikt. Men moet evenmin de begunstiging zo redigeren, dat de erfgenamen de uitkering zouden ontvangen, daar dan weer successierecht kan worden geheven over het bedrag der uitkering.

De juiste constructie voor de compagnonsverzekering is bij de huidige jurisprudentie die waarbij de vennoten zich jegens elkaar verplichten een verzekering te sluiten in zodanige vorm dat bij overlijden van de andere vennoot een kapitaal tot uitkering komt. Vennoot A sluit dus op het leven van vennoot B en vennoot $B$ op het leven van vennoot $A$. Deze verzekering kan ook in één polis worden gesloten, met als voordeel een lager tarief, mits nauwkeurig is aangegeven wat, actuarieel berekend, ieders aandeel in de totale premie is. Deze verzekeringsvorm blijft ook dan een in privé getroffen financieringsmaatregel.

\section{De naamloze vennootschap}

De naamloze vennootschap lijkt de bij uitstek geschikte figuur om de continuïteit van de onderneming te handhaven. Ten aanzien van de leiding van de onderneming kunnen hier alle nodige voorzieningen worden getroffen. Bij overlijden van de oprichter-grootaandeelhouder kan worden volstaan met toedeling aan de erven van de aandelen in de N.V.

Zo eenvoudig liggen echter de zaken doorgaans niet. In vele gevallen heeft men de N.V.-vorm tevens voor de fiscale voordelen gekozen en de gemaakte winsten in het bedrijf aangewend (zelffinanciering). In andere gevallen heeft men gebruik gemaakt van de mogelijkheid tot geruisloze overgang naar de N.V.-vorm,

m a b blz. 371 
waardoor van meet af aan vrij grote stille reserves anwezig zijn. Het effect is in beide gevallen gelijk. De waarde van de onderneming wordt niet weerspiegeld in het dividend dat op de aandelen wordt uitgekeerd. De oprichters, meestal tevens bestuurders van de N.V. hebben daar overigens weinig belang bij; het gaat hen om het rendabel maken van het in de N.V. geïnvesteerde vermogen. Men heeft een duurzaam belang bij haar voortbestaan.

Indien door vererving of anderszins de band tussen de N.V. en haar aandeelhouders losser wordt, ontstaat vaak de figuur dat de nieuwe aandeelhouders geen belang stellen in de versterking en uitbreiding van de onderneming maar vooral belang hebben bij het rendement dat hun bezit oplevert.

In deze familievennootschappen hebben de aandeelhouders vrijwel steeds cen bezit van zodanige betekenis, dat fiscaal sprake is van zgn. ,aanmerkelijk belang” bij de N.V. Deze materie is thans geregeld in artikel 19, 2e lid van het Besluit op de Inkomstenbelasting. Bij wetsfictie worden de houders van een aanmerkelijk belang geacht een bedrijf uit te oefenen. Een aanmerkelijk belang wordt aanwezig geacht, indien de vervreemder, hetzij alleen, hetzij tezamen met zijn verwanten, in de loop van de laatste vijf jaren voor meer dan een vierde gedeelte van het nominaal gestorte kapitaal middellijk of onmiddellijk aandeelhouder is geweest. Hierbij worden uitsluitend als verwanten beschouwd de echtgenote, de bloed- en aanverwanten in de rechte linie en die in de tweede graad der zijlinie (broers, zusters, schoonzusters en zwagers).

Wanneer de betrokken aandeelhouder, door vervreemding van aandelen zijn portie in de open, stille en geheime reserves van de N.V. realiseert, openbaart het fictieve bedrijf van ,aanmerkelijk-belang-aandeelhouder” zijn fiscale gevolgen.

$\mathrm{Bij}$ verkoop aan derden wordt belast het verschil tussen verkoopprijs en verkrijgingsprijs op de voet van artikel $48(20-40 \%)$.

Bij verkoop aan de N.V. zelf wordt belast naar het bijzondere tarief het verschil tussen verkoopprijs en verkrijgingsprijs en in daartoe leidende gevallen bovendien naar het progressieve tarief het verschil tussen de verkrijgingsprijs en hetgeen op de aandelen is gestort. Deze fiscale claim vervalt in de huidige wetgeving wanneer de aandelen door schenking of vererving op anderen overgaan. Als verkrijgingsprijs voor de nieuwe eigenaren geldt de geldwaarde ten tijde van de schenking of vererving. Door schenking bij leven of vererving kan de fiscale claim dus worden ontgaan.

Het Wetsontwerp op de Inkomstenbelasting 1960 maakt hieraan een einde. Bij schenking wordt krachtens artikel $34,5 \mathrm{e}$ lid van het Wetsontwerp als vervreemdingsprijs voor de schenker in aanmerking genomen de waarde ten tijde van de schenking. De belasting eist dan zijn tol, zij het dan tegen een vast belastingpercentage van 20 (artikel 48 van het ontwerp).

De verkrijgingskosten van aandelen die aan de vervreemder zijn opgekomen krachtens erfrecht stelt het negende lid van artikel 34 op het bedrag dat vcor de erflater geldt. Het gevolg hiervan is dat de op de aandelen rustende fiscale claim op de verkrijger overgaat. Ten aanzien van aandelen welke vóór de invoering van de nieuwe wet zijn verkregen door vererving wordt de belaste winst bij vervreemding gesteld op het verschil tussen overdrachtsprijs en de geldswaarde van die aandelen ten tijde van die vererving.

De erfgentmen kunnen onder de werking van de nieuwe wet de fiscale claim

m a b blz. 372 
afrekenen. De geldswaarde wordt dan op dezelfde wijze bepaald als bij schenking en de erflater belast à $20 \%$ van de gemaakte winst. Deze afrekening heeft ons inziens geen enkele zin, daar deze tegen hetzelfde tarief plaatsvindt dat in de toekomst zou moeten worden voldaan bij verkoop. Gunstiger is de bepaling (artikel 34, 3e lid) die het aanmerkelijk belang eerst laat beginnen wanneer men - al dan niet tezamen met zijn echtgenoot - voor meer dan $5 \%$ van het nominaal gestorte kapitaal onmiddellijk of middellijk aandeelhouder is geweest. Hierdoor worden de kleine aandeelhouders van de fiscale claim ontheven, die door de familie-relatie op hen rustte.

Eveneens is een verzachting aangebracht door de bepaling (opgenomen in artikel 48 van het ontwerp) dat het bijzondere tarief (20-40\%) van toepassing zal zijn bij inkoop door een vennootschap van alle aandelen van een aandeelhouder in die vennootschap, mits die aandelen meer dan $5 \%$ van het nominaal gestorte kapitaal vertegenwoordigen.

De statuten van familie-vennootschappen beperken veelal de overdracht van aandelen door een aanbiedingsplicht aan de overige aandeelhouders in de N.V. Eerst wanneer deze niet als gegadigden wensten op te treden is de aanbieder vrij te verkopen aan wie hij verkiest.

$\mathrm{Bij}$ vererving van het aandeelbezit moet ook thans in elk geval successierecht worden betaald over de geldswaarde der vererfde aandelen. Wanneer het vermogen van de erflater voor het merendeel bestond uit aandelen in een besloten N.V., lopen de erfgenamen kans door de heffing van dit recht in betalingsmoeilijkheden te komen, welke zullen leiden tot een aandrang op de N.V. tot uitkering, c.q. inkoop van aandelen. De geldswaarde van de aandelen moet volgens de huidige jurisprudentie ${ }^{3}$ ) worden bepaald met behulp van objectieve maatstaven in dien zin dat daarbij geen rekening wordt gehouden met de subjectieve omstandigheden, die de waarde der effecten als bestanddeel van het vermogen juist van de erflater of wel de verkrijger bepalen of mede bepalen. Bij vererving van een meerderheidspakket kan daardoor een veel hogere koers worden bepaald dan bij een minderheidspakket.

Voor de vermogensbelasting speelt hetzelfde begrip geldswaarde eveneens een rol. Bij een hoge geldswaarde en een matige dividenduitkering is het mogelijk dat het gehele dividend aan belasting moet worden uitgegeven. Een voorbeeld moge dit verduidelijken. Een aandeel met een geldswaarde van $500 \%$ geeft een dividend van $5 \%$. De aandeelhouder betaalt $50 \%$ Inkomstenbelasting. Van zijn dividend houdt hij $21 / 2 \%$ over, die dan net voldoende zijn ter betaling van de Vermogensbelasting. ${ }^{4}$ )

Gezien het bovenstaande zal de groot-aandeelhouder bij zijn leven maatregelen moeten treffen opdat straks zijn erfgenamen niet op grond van aan de fiscus verschuldigde belastingen een aanslag plegen op de middelen van de N.V. en daardoor haar continuïteit in gevaar zouden brengen. Voorzover de erfgenamen de successierechten niet uit het overig vermogen (of eigen vermogen) zouden kunnen voldoen, dient de aandeelhouder hiertoe bedragen te reserveren.

3) Arrest Hoge Raad van 14 februari 1962, rolno. 14738 (BND 1962/94)

4) In het Wetsontwerp op de Vermogensbelasting is een aftrekmogelijkheid opgenomen ter zake van de fiscale claim bij verkoop. Deze aftrek bedraagt $5 \%$ van het verschil tussen verkrijgingsprijs en geldswaarde. 